\title{
Precut esophageal endoscopic mucosal resection for cervical esophageal cancer to minimize mucosal defect
}

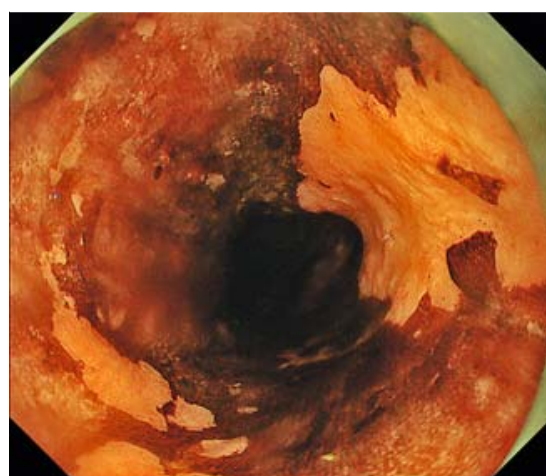

Fig. 1 Two adjacent, shallow depressed, iodine-unstained lesions, $25 \mathrm{~mm}$ and $8 \mathrm{~mm}$ in size, were found in the cervical esophagus.

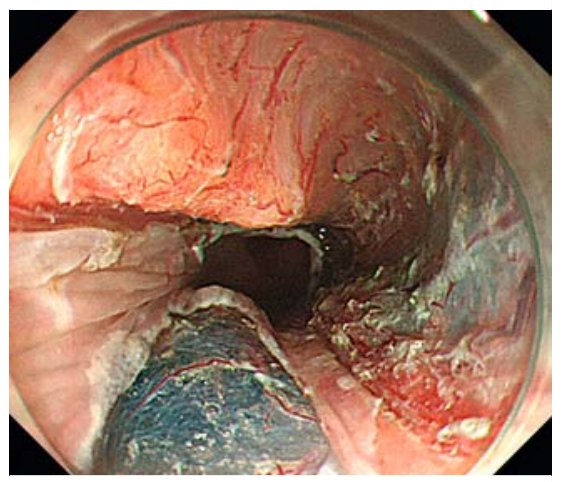

Fig. 4 The two lesions were resected and non-neoplastic mucosa was left between them.

A 72-year-old man underwent esophagogastroduodenoscopy (EGD) for heartburn. Two adjacent, iodine-unstained, shallow depressed lesions, $25 \mathrm{~mm}$ and $8 \mathrm{~mm}$ in size, were found in the cervical esophagus (> Fig.1). Biopsies revealed squamous cell carcinoma (SCC). The patient opted for endoscopic resection.

Peripheral endoscopic markings were performed using the tip of a DualKnife J (KD-655; Olympus Tokyo, Japan) ( Fig. 2). En bloc resection was achieved for the first lesion after standard endoscopic submucosal dissection (ESD). Pre-

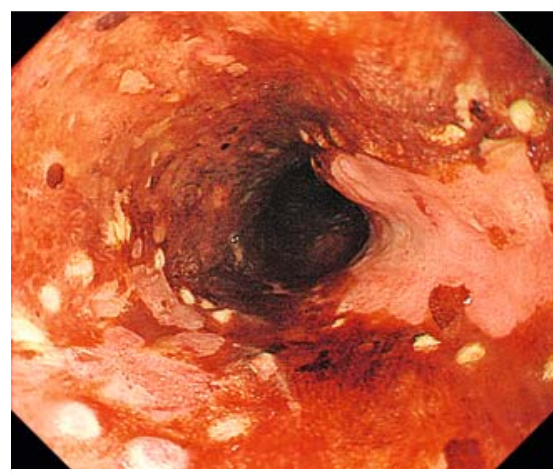

- Fig. 2 Endoscopic peripheral markings were performed around both lesions with the tip of a DualKnife J (KD-655; Olympus Tokyo, Japan).

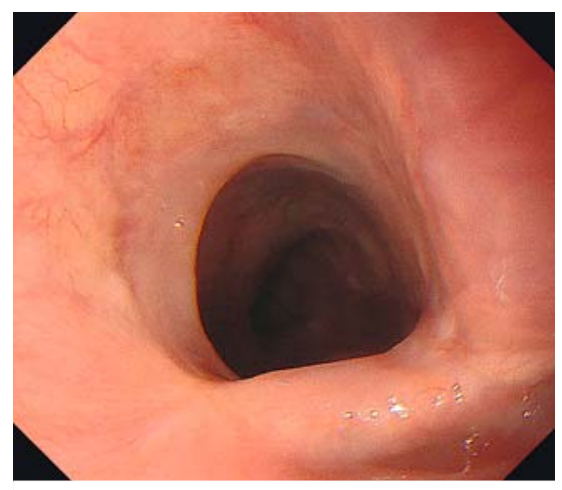

- Fig.5 No stricture occurred following esophageal endoscopic mucosal resection.

cut endoscopic mucosal resection (EMR) was performed for the second lesion ( Video 1). A circumferential mucosal incision was performed using the DualKnife J ( Fig. 3), followed by cap-assisted EMR (EMR-C) using a single-channel endoscope (Q260]; Olympus). Saline with diluted indigo carmine was injected into the submucosa. The gastroscope was withdrawn, and a crescent-shaped electrocautery snare (SD-221L-25; Olympus) was opened within the oblique transparent cap with an internal circumferential ridge (MAJ-290; Olympus). The area

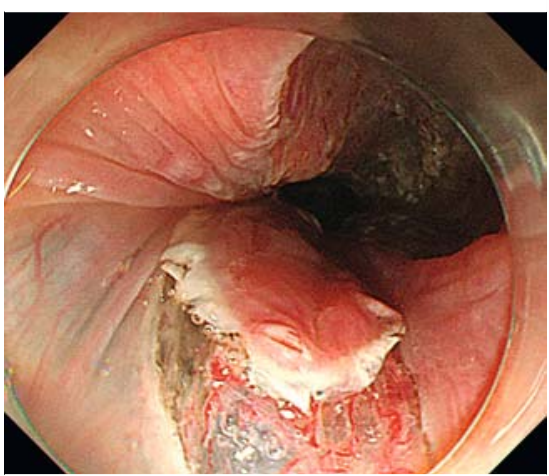

-Fig. 3 Circumferential mucosal incision around the markings was performed using a DualKnife J (KD-655; Olympus Tokyo, Japan).

within the mucosal incision was suctioned into the cap and captured by tightening the snare. This procedure allowed for en bloc resection of both lesions while preserving non-neoplastic mucosa between the two ( $\mathbf{F i g . 4}$ ). The resected specimens revealed SCC, with deepest invasion to the lamina propria mucosa without lymphovascular invasion, and free margins. No dysphagia occurred postprocedure and follow-up EGD 8 weeks later revealed no post-procedure stricture ( $\triangleright$ Fig. 5).

Extensive ESD is a high-risk procedure for post-ESD stricture, particularly in the cervical esophagus [1]. Standard EMR-C is straightforward and time-saving for small esophageal cancers [2,3]. However, in this case it would have been challenging to maintain optimal non-neoplastic mucosa between the two lesions. ESD for small esophageal cancer is arduous as it is technically difficult to enter the submucosal space. Precut EMR-C was effective in our patient to achieve R0 resection with minimal lateral margin, hence avoiding extensive resection with potential post-procedure stricture.

Endoscopy_UCTN_Code_TTT_1AO_2AG 


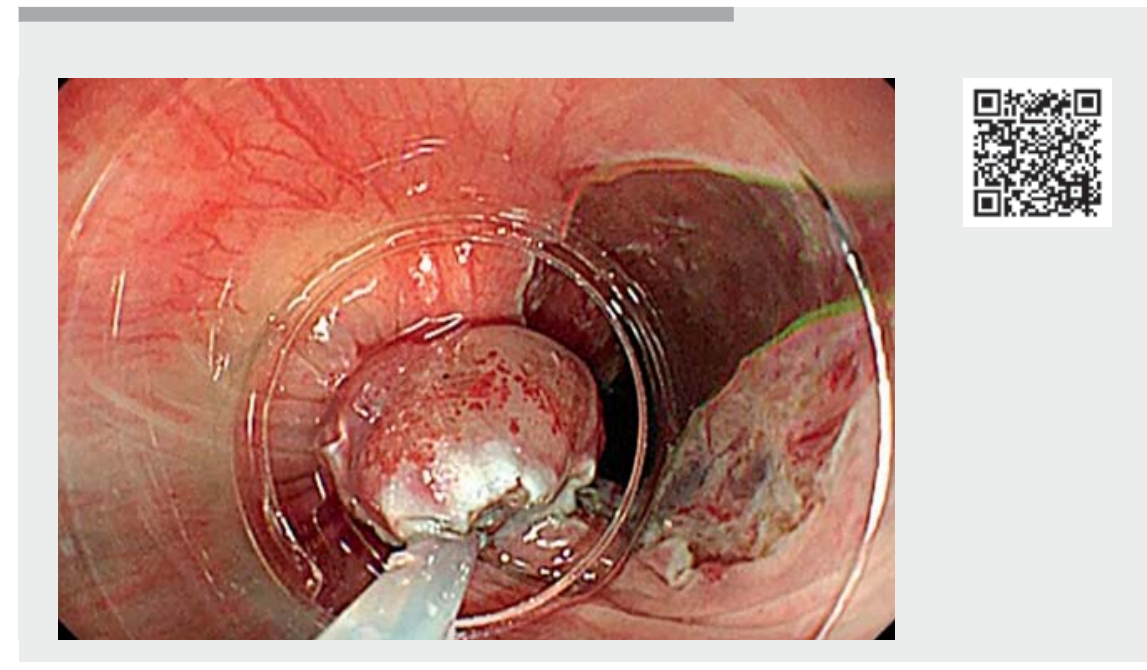

$\checkmark$ Video 1 Precut cap-assisted endoscopic mucosal resection (EMR-C) was performed for the cervical esophageal squamous cell carcinoma. Circumferential mucosal incision was performed using a DualKnife J (KD-655; Olympus Tokyo, Japan), followed by EMR-C.

\section{Acknowledgments}

We would like to thank Drs. Satoru Nonaka and Shih Yea Sylvia Wu, Endoscopy Division, National Cancer Center Hospital, Tokyo, Japan, for their kind support with this paper.

\section{Competing interests}

The authors declare that they have no conflict of interest.

The authors

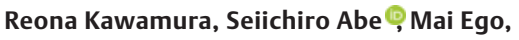
Haruhisa Suzuki, Shigetaka Yoshinaga, Ichiro Oda, Yutaka Saito

Endoscopy Division, National Cancer Center Hospital, Tokyo, Japan
[1] lizuka T, Kikuchi D, Hoteya S et al. Efficacy and safety of endoscopic submucosal dissection for superficial cancer of the cervical esophagus. Endosc Int Open 2017; 5: 736741

[2] Kawashima K, Abe S, Koga M et al. Optimal selection of endoscopic resection in patients with esophageal squamous cell carcinoma: endoscopic mucosal resection versus endoscopic submucosal dissection according to lesion size. Dis Esophagus 2020. doi:10.1093/dote/doaa096
[3] Inoue $\mathrm{H}$, Endo M, Takeshita K et al. A new simplified technique of endoscopic esophageal mucosal resection using a cap-fitted panendoscope (EMRC). Surg Endosc 1992; 6: 264-265

\section{Bibliography}

Endoscopy 2022; 54: E81-E82

DOI $10.1055 / a-1388-6348$

ISSN 0013-726X

published online 15.3.2021

(c) 2021. Thieme. All rights reserved.

Georg Thieme Verlag KG, Rüdigerstraße 14, 70469 Stuttgart, Germany

\section{ENDOSCOPY E-VIDEOS \\ https://eref.thieme.de/e-videos}

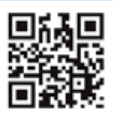

Endoscopy E-Videos is an open access online section, reporting on interesting cases and new techniques in gastroenterological endoscopy. All papers include a high quality video and all contributions are freely accessible online. Processing charges apply (currently EUR 375), discounts and wavers acc. to HINARI are available.

This section has its own submission website at https://mc.manuscriptcentral.com/e-videos 